\title{
A computer tomography-based anthropomorphic study of forearm osteology: implications for prosthetic design
}

\author{
Henry S Pretorius, ${ }^{*}$ (D) Nando Ferreira, Marilize C Burger \\ Division of Orthopaedic Surgery, Department of Surgical Sciences, Faculty of Medicine and Health Sciences, Stellenbosch University,
} Cape Town, South Africa

*Corresponding author: hsp359@sun.ac.za

Citation: Pretorius HS, Ferreira N, Burger MC. A computer tomography-based anthropomorphic study of forearm osteology: implications for prosthetic design. SA Orthop J 2021;20(3):162-166. http://dx.doi. org/10.17159/2309-8309/2021/ v20n3a5

Editor: Prof. Sithombo Maqungo, University of Cape Town, Cape Town, South Africa

Received: September 2020

Accepted: January 2021

Published: August 2021

Copyright: (c) 2021 Pretorius

$\mathrm{HS}$. This is an open-access article distributed under the terms of the Creative Commons Attribution Licence, which permits unrestricted use, distribution and reproduction in any medium, provided the original author and source are credited.

Funding: No funding was received for this study.

Conflict of interest: The authors declare they have no conflicts of interest that are directly or indirectly related to the research.

\section{Abstract \\ Background}

The aim of this study was to accurately establish the variability in the anatomy of the radius and ulna in the context of the design of an intramedullary nail for both bones.

\section{Methods}

Forearm computed tomography scans were used to measure the specific internal and external anatomy of the radius and ulna in adult patients. Patients with fractures or dislocations involving either the radius and/or ulna were excluded.

\section{Results}

A total of 97 scans, comprising $84 \%$ male and $16 \%$ female patients, were included. The mean radius length was $238.43 \pm 18.38 \mathrm{~mm}(95 \% \mathrm{Cl} 234.60-241.74 \mathrm{~mm})$. The mean curvature was an arc with a radius of $561.43 \pm 93.49 \mathrm{~mm}(95 \% \mathrm{Cl} 543.09-580.78 \mathrm{~mm})$. The smallest measurement of the canal width was $5.17 \mathrm{~mm}(95 \% \mathrm{Cl} 4.87-5.47 \mathrm{~mm})$. The ulna showed a mean length of $259.90 \pm 19.88 \mathrm{~mm}(95 \% \mathrm{Cl} 255.89-263.91 \mathrm{~mm})$. The smallest measurement of the canal width was $4.80 \pm 1.30 \mathrm{~mm}(95 \% \mathrm{Cl} 4.53-5.87 \mathrm{~mm})$. The mean proximal shaft angle was $11.39 \pm 3.30^{\circ}$ $\left(95 \% \mathrm{Cl} 10.76-12.82^{\circ}\right)$.

\section{Conclusion}

This computed tomography scan-based anthropomorphic study has identified novel anatomical features and associations of human forearm bones. This information will be used in the design and manufacture of anatomic intramedullary devices to better manage radius and ulna fractures or pathology.

Level of evidence: Level 4

Keywords: radius, ulna, anatomy, osteology, radius of curvature, intramedullary design

\section{Introduction}

The radius and ulna are commonly fractured bones, ${ }^{1}$ but despite the frequency with which these bones are injured, studies that describe their anatomy are limited. The specifically relevant anatomy of the internal osteology makes the design of new implants challenging as few studies relate to the canal size or radius of curvature..$^{2-4}$ In-depth anatomical studies can be used to design the shape and size of implants and will also take advantage of the anatomical relationships that relate implant size or length, which can be extrapolated by measuring specific areas of anatomy, for example, measuring the ulna to extrapolate the radial length..$^{5-7}$ Due to the diverse injury patterns and numerous strategies of surgical management, a thorough understanding of the anatomy is of paramount importance. In support of this, studies by Beşer et al. and others explored the anatomy of the ulna at the elbow joint and concluded that correctly measured angulations can help the design surgeon develop better prostheses and thereby maintain function of the elbow joint. ${ }^{8-12}$ This study, however, was limited to analysis of cadaveric specimens.

The challenge of anatomical studies is that the architecture of the bone often has to be destroyed in order to measure specific parameters. ${ }^{4}$ To circumvent this, Itamura et al. ${ }^{2}$ used computed tomography (CT) scans of the proximal radius of cadaveric specimens. The results demonstrated a clear shape mismatch of the native radial head and available radial head replacement prostheses which could lead to jamming at the radio-capitellar and proximal radioulnar joints. ${ }^{2}$ The paucity in the literature regarding radius and ulna anatomy is noted as well as previously reported studies with numbers less than $40,,^{2,13}$ with the notable exception of Rouleau et al. who scanned only the proximal ulna $(n=100) \cdot{ }^{14}$

The morphology of the proximal and distal radius has been studied in great detail. Limited literature on the radius of curvature of the radius makes accurate reconstruction of this curvature when treating forearm fractures challenging. ${ }^{11}$ The clinical significance is that the union rates are improved for fractures where the anatomy 
has been restored. ${ }^{15,16}$ Apart from the radius of curvature of the radius that remains to be better defined, the relationship and relative length of the radius and ulna also need to be established.

The aim of this study was therefore to describe the anatomy of the radius and ulna of individuals that underwent forearm CT scans.

\section{Methods}

A retrospective anatomical study of the radius and ulna of patients that underwent forearm CT scan was conducted. Institutional ethics committee approval as well as institutional clearance was obtained prior to commencement of data collection. The hospital picture archiving and communication system (PACS) database was searched for all forearm scans that fitted the study criteria. Specifically, all patients older than 18 years, presenting between January 2014 and October 2015, who subsequently received a CT scan of their forearm were considered for inclusion. Any patients with fractures of the radius and/or ulna or any other anatomical deformities were excluded.

All CT scans were performed with a Siemens SOMATOM Emotion 6 with minimum slice thicknesses of $0.23 \mathrm{~mm}$. The image files were stored as Digital Imaging and Communications in Medicine format (DICOM) files. All measurements were made using RadiAnt 4.2.1 (Medixant, Poland) DICOM viewing software.

The collected images were processed using image processing software, and measurements were taken by a single investigator. To standardise the measurements, the images were visualised in a multiplanar reconstruction mode (MPR). Measurements of specific

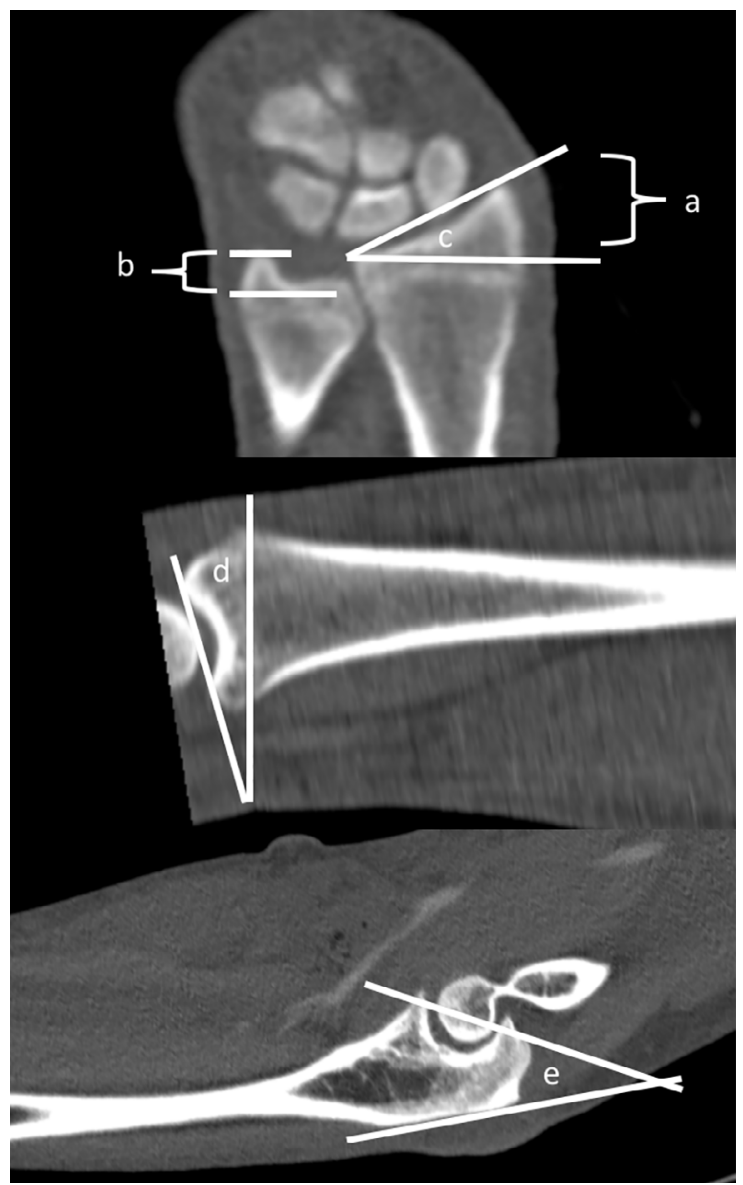

Figure 1. Periarticular measurements of a) radius styloid length; b) ulna styloid length; c) radial inclination; d) radial tilt; e) proximal ulna olecranon angle anatomical areas were taken to highlight the pertinent anatomy, and included (Figures 1-5):

The radius:

1. Overall length from the midpoint of the wrist to the centre of the radial head

2. Radius of curvature of the shaft of the radius (length from the middle of the shaft proximally where the neck ends and the curved shaft begins, and the distance from the previous line to the apex of the arc)

The radius of curvature uses the arc height $(h)$ and curve length (w) in the formula:

Radius of curvature $=\frac{h}{2}+\frac{w^{2}}{8 h}$

3. Canal diameter in the middle of the bone and at the midpoints of the proximal and distal shafts

4. Cortical diameter of the radius at the neck, proximal, middle and distal shaft

5. Size of the radial head in height and diameter measured in relation to the radial tuberosity

6. Maximum angle between the radius neck and radius shaft

7. Radius tilt, inclination and styloid length of the distal radius

8. Distal radial height including Lister's tubercle, and width of the distal radius

The ulna:

1. Overall length from the midpoint of the olecranon to the centre of the distal ulna

2. Olecranon articular angle

3. Cortical thickness of the ulna at the proximal, middle and distal shaft

4. Canal diameter of the ulna at the proximal, middle and distal shaft

5. Size of the ulna head measured in the plane of the styloid and at $90^{\circ}$ to the plane

6. Angle between the olecranon and ulna shaft

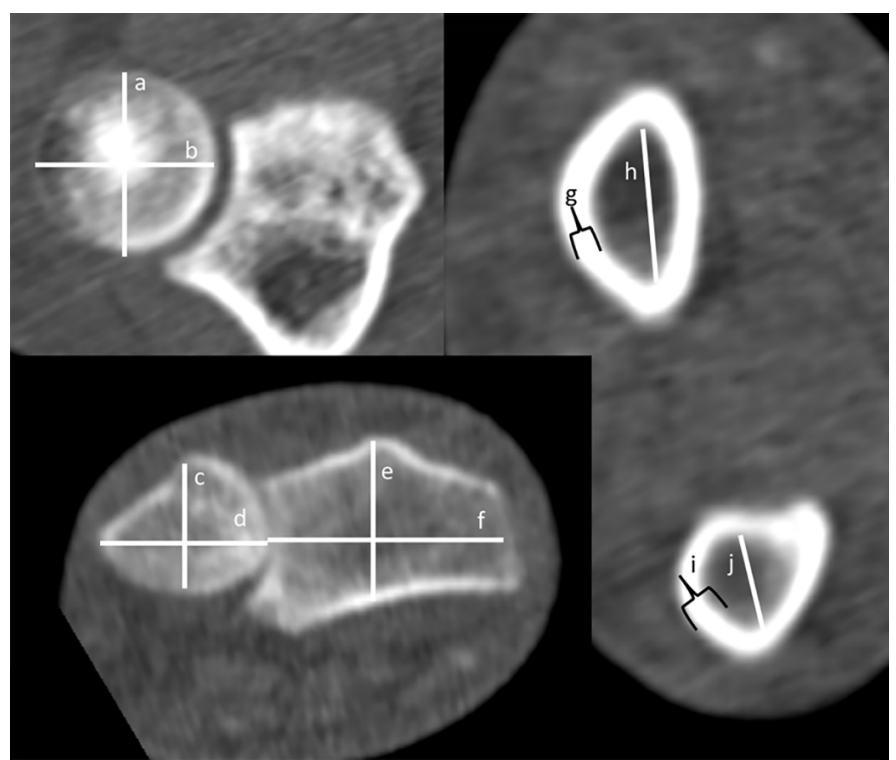

Figure 2. Axial CT cuts showing the measurements of the a) radial head in the plane of the tuberosity; b) radial head $90^{\circ}$ to the plane of the tuberosity; c) ulna head $90^{\circ}$ to the plane of the styloid; d) ulna head in the plane of the styloid; $e-f$ ) the height and width of the distal radius; $g-j$ ) medulla and cortical measurements of the shafts of both bones 

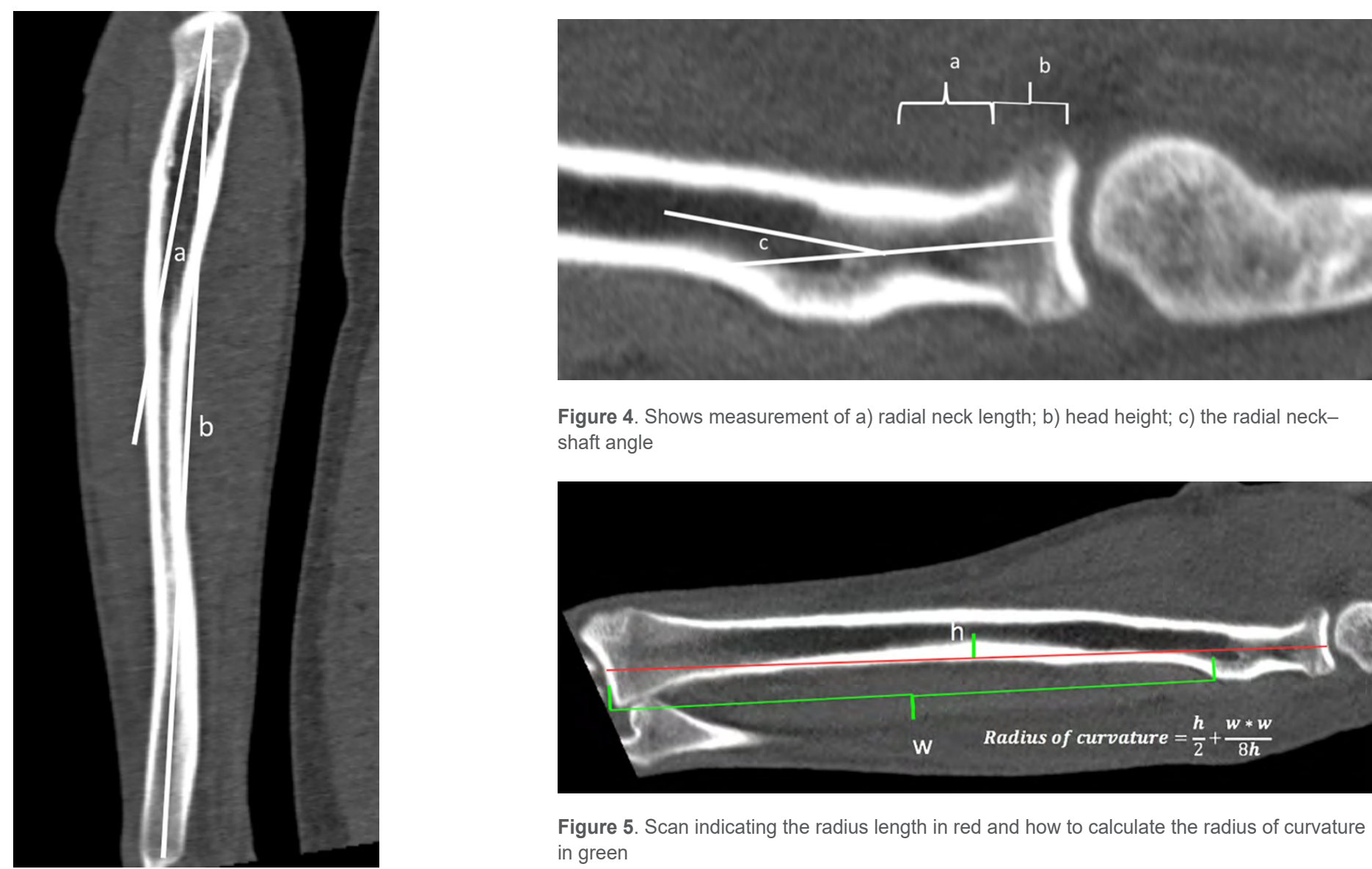

Figure 4. Shows measurement of a) radial neck length; b) head height; c) the radial neckshaft angle

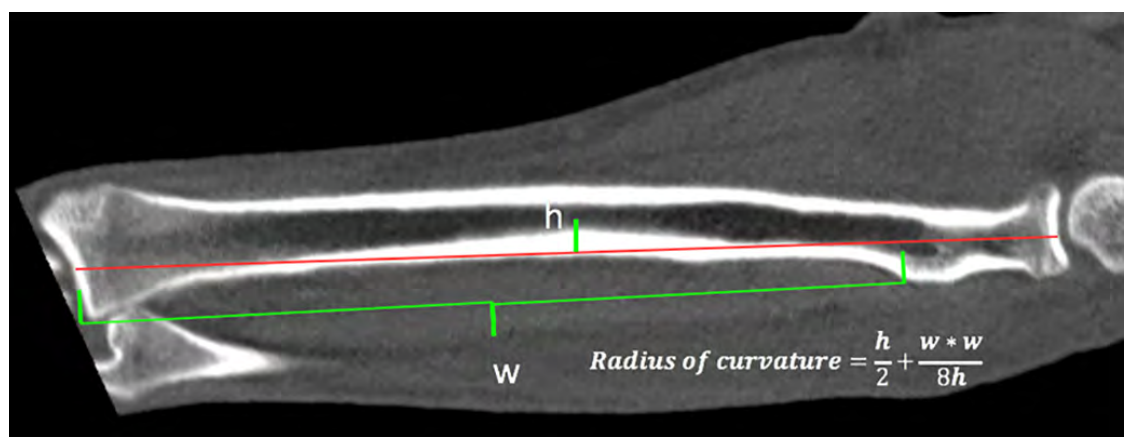

Figure 5. Scan indicating the radius length in red and how to calculate the radius of curvature in green

Figure 3. Showing a) the proximal ulna shaft angle; b) ulna length measurement

Data was analysed using STATISTICA (v13, TIBCO Software). Considering the anatomical nature of the measurements taken, all data was normally distributed as expected. Data is described as means \pm standard deviations (SDs) with $95 \%$ confidence intervals (Cl) indicated in parentheses. Categorical data is described as frequencies with the count indicated in parentheses.

\section{Results}

A total of 97 scans were included with an equal distribution between left $(49 \%, n=47)$ and right $(51 \%, n=49)$ forearms. The cohort consisted of predominantly male patients $(84 \%, \mathrm{n}=82)$ with a mean age of $34.91 \pm 13.33$ years $(95 \% \mathrm{Cl} 32.22-37.59)$.

The majority of scans $(84 \%, n=81)$ were performed following trauma, which included $54(56 \%)$ stab wounds, and $22(23 \%)$ gunshot-related injuries. The non-traumatic indications $(16 \%$, $\mathrm{n}=16$ ) scans were performed for vascular or other medical reasons (Figure 6).

Table I shows the measurement results for the radius and ulna. The mean radius length was $238.43 \pm 18.38 \mathrm{~mm}(95 \% \mathrm{Cl}$ 234.60-241.74 $\mathrm{mm}$ ), with the mean curvature being an arc with a radius of $561.43 \pm 93.49 \mathrm{~mm}(95 \%$ Cl $543.09-580.78 \mathrm{~mm})$ and the smallest measurement of the radial canal width being $5.17 \mathrm{~mm}(95 \% \mathrm{Cl} 4.87-5.47 \mathrm{~mm})$. The study shows the radial styloid length of $10.55 \pm 2.13 \mathrm{~mm}(95 \% \mathrm{Cl} 10.12-10.98 \mathrm{~mm})$ and the radial inclination $20.99 \pm 2.50^{\circ}\left(95 \% \mathrm{Cl} 20.48-21.49^{\circ}\right)$ as well as volar tilt $12.94 \pm 3.68^{\circ}\left(95 \% \mathrm{Cl} 12.20-13.68^{\circ}\right)$. The distal radius height including Lister's tubercle measured $23.06 \pm 2.80 \mathrm{~mm}(95 \%$ Cl 22.49-23.62 mm).

The ulna showed a mean length of $259.90 \pm 19.88 \mathrm{~mm}(95 \%$ Cl 255.89-263.91 mm) with the smallest measurement of the ulna canal width being $4.80 \pm 1.30 \mathrm{~mm}(95 \% \mathrm{Cl} 4.53-5.87 \mathrm{~mm})$. The mean proximal shaft angle was $11.39 \pm 3.30^{\circ}(95 \% \mathrm{Cl} 10.76-$ $\left.12.82^{\circ}\right)$.

\section{Discussion}

The aim of this study was to accurately establish the variability in the anatomy of the radius and ulna in the context of the design of intramedullary nails for both bones by assessing CT scans.

When considering the anatomy of the radius, the results are useful in the context of implant design. When the curvature of the radius is discussed, the coronal curve of the radius is not the same as the measurement referred to as the bow of the radius. The bow of the radius is measured as the distance from a longitudinal line connecting the cortex at the level of the radial tuberosity and the ulna border of the distal radius at the radioulnar joint to the radius cortex at its furthest point. As the medullary canal and

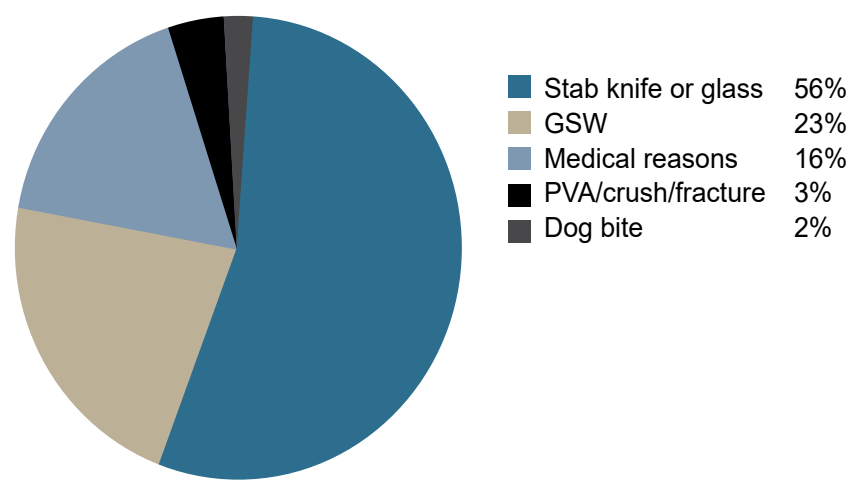

Figure 6. Indications for CT scans 
Table I: Measurement results for radius and ulna

\begin{tabular}{|c|c|}
\hline Variable & $\begin{array}{c}\text { MeantSD }(95 \% \mathrm{CI}) \\
n=97\end{array}$ \\
\hline Radius length mm (centre of head to centre of distal radius) & $238.43 \pm 18.38(234.72-242.13)$ \\
\hline Radius of curvature mm (height) & $8.64 \pm 1.31(8.37-8.90)$ \\
\hline Radius of curvature mm (curve length) & $194.43 \pm 15.12(191.38-97.48)$ \\
\hline Radius of curvature & $561.93 \pm 93.49(543.09-580.78)$ \\
\hline Radial head diameter mm (plane of tuberosity) & $23.97 \pm 2.32(23.50-24.43)$ \\
\hline Radial head diameter $\mathrm{mm}$ ( $90^{\circ}$ to plane of tuberosity) & $23.30 \pm 2.41(22.82-23.79)$ \\
\hline Radial neck max angle deg & $10.84 \pm 2.58(10.32-11.36)$ \\
\hline Radial neck length mm & $35.40 \pm 9.44(33.5-37.3)$ \\
\hline Radial neck cortical thickness $\mathrm{mm}$ & $4.51 \pm 1.19(4.27-4.75)$ \\
\hline Radial neck canal max diameter mm & $7.55 \pm 1.89(7.17-7.93)$ \\
\hline Radial head height $\mathrm{mm}$ & $8.24 \pm 2.55(7.72-8.75)$ \\
\hline Radial canal max diameter mm (proximal $1 / 3$ of curved canal) & $6.33 \pm 1.57(6.01-6.65)$ \\
\hline Radial canal max diameter mm (middle of curved canal) & $5.53 \pm 1.58(5.21-5.84)$ \\
\hline Radial canal max diameter mm (distal $1 / 3$ of curved canal) & $8.76 \pm 2.65(8.23-9.3)$ \\
\hline Radial canal min diameter mm & $5.17 \pm 1.48(4.87-5.47)$ \\
\hline Radial inclination deg & $20.99 \pm 2.50(20.48-21.49)$ \\
\hline Volar tilt deg & $12.94 \pm 3.68(12.20-13.68)$ \\
\hline Distal radius styloid length $\mathrm{mm}$ & $10.55 \pm 2.13(10.12-10.98)$ \\
\hline Distal radius max width $\mathrm{mm}$ & $30.46 \pm 3.15(29.83-31.10)$ \\
\hline Distal radius max height mm (including Lister) & $23.06 \pm 2.80(22.49-23.62)$ \\
\hline Varus angulation proximal deg & $11.39 \pm 3.13(10.76-12.02)$ \\
\hline Ulna length mm (centre of olecranon to centre of ulna head) & $259.9 \pm 19.88(255.89-263.91)$ \\
\hline Ulna max styloid length mm & $5.41 \pm 1.40(5.13-5.69)$ \\
\hline Ulna head diameter mm (plane of styloid) & $19.54 \pm 2.15(19.1-19.97)$ \\
\hline Ulna head diameter $\mathrm{mm}\left(90^{\circ}\right.$ to plane of styloid $)$ & $16.77 \pm 2.07(16.35-17.19)$ \\
\hline Ulna canal max diameter mm (proximal $1 / 3$ of curved canal) & $7.25 \pm 2.45(6.75-7.74)$ \\
\hline Ulna canal max diameter mm (middle of curved canal) & $5.4 \pm 1.5(5.09-5.70)$ \\
\hline Ulna canal max diameter mm (distal $1 / 3$ of curved canal) & $5.33 \pm 1.38(5.05-5.61)$ \\
\hline Ulna canal min diameter mm & $4.80 \pm 1.30(4.53-5.06)$ \\
\hline
\end{tabular}

cortical margin of the radius are not parallel, and the radius of curvature is related to the canal of the radius, it stands to reason that the measurements should be in the medullary cavity of the radius or parallel to that on the outer cortex. This is done using the centre of the canal at the start and end of the curve with the mathematical formula given above. The clinical relevance is that an intramedullary implant with a curvature that recreates the bow of the radius will lead to better union rates. ${ }^{15}$ Our findings confirm a mean radius of curvature for most forearms of $561.93 \mathrm{~mm}$, with the $95 \% \mathrm{Cl}$ between 543.09 and $580.78 \mathrm{~mm}$.

When considering nail length, we can be confident that an implant length ranging from 220 to $270 \mathrm{~mm}$ (radius $238.43 \pm 18.38$, ulna $259.9 \pm 19.88$ ) would represent the shortest radius and the longest ulna in our study population. Additionally, by using $10 \mathrm{~mm}$ increments, the nails will be appropriate for most individuals that might require treatment. With respect to canal size, an implant size of $4.5 \mathrm{~mm}$ would allow passage through the $5 \mathrm{~mm}$ canal observed in our cohort. The distal height of the radius and the proximal diameter of the ulna allows enough space for the $6 \mathrm{~mm}$ nail locking block.
The mean distal radius height was found to be $23.06 \mathrm{~mm}$ (SD 2.80, range $14.70-33.30$ ) with the $95 \% \mathrm{Cl}$ being between 22 and $24 \mathrm{~mm}$. This observed height can potentially be extrapolated to the length of screws one might need for distal locking plates, thus alleviating the need to manufacture screws far outside of the observed range. This limited range might potentially lead to a cost and inventory advantage for implant manufacturers.

The study confirms some features of previous studies on the Rule of 11 with the styloid length, volar inclination and radial inclination being $11 \mathrm{~mm}, 11^{\circ}$ and $22^{\circ}(2 \times 11)$, where this is used for decision-making in distal radius fractures. ${ }^{17}$ The study shows the radial styloid length of $10.55 \pm 2.13 \mathrm{~mm}(95 \% \mathrm{Cl} 10.12-$ $10.98 \mathrm{~mm}$ ) and the radial inclination $20.99 \pm 2.50^{\circ}(95 \% \mathrm{Cl} 20.48-$ $\left.21.49^{\circ}\right)$, which are in keeping with previously held ideas. The volar tilt of $12.94 \pm 3.68^{\circ}\left(95 \% \mathrm{Cl} 12.20-13.68^{\circ}\right)$ is larger than previously described as $11^{\circ}$ and this may have relevance to distal radius fracture management.

Although the sample size of 97 scans is limited, this sample is significantly larger than previously reported studies which included a cadaver study $(n=12)^{13}$ and a similar CT study $(n=22)^{2}$ with the 
notable exception of Rouleau et al. who scanned only the proximal ulna $(n=100)$. Although most patients included in the current study were male, this is potentially the population group that would most require the use of a forearm intramedullary nail. Future studies could potentially repeat these investigations in female-dominated samples. Although our tertiary institution serves a mixed demographic of patients, it is still only including measurements from one geographical area surrounding our hospital; however, we do not anticipate that patient demographics within South Africa will play a large role in variation. There might, however, be variation in other population groups outside of South Africa, which should be the target of future investigations.

This study formed part of a larger study that aims to investigate statistical shape modelling for future predictive models. The present study was the first and investigated the anatomical features of the two most often fractured forearm bones.

\section{Conclusion}

This CT scan-based anthropomorphic study has identified novel anatomical features and associations of human forearm bones. This information will be used in the design and manufacture of anatomic intramedullary devices to better manage specific radius and ulna fractures or pathology.

\section{Acknowledgements}

Dr Nabeela Adam for the initial measuring and data capturing; Dr Rudolph Venter was integral in the study design for CT anatomical studies.

\section{Ethics statement}

The authors declare that this submission is in accordance with the principles laid down by the Responsible Research Publication Position Statements as developed at the 2nd World Conference on Research Integrity in Singapore, 2010.

Prior to commencement of the study ethical approval was obtained from the following ethical review board: Stellenbosch University Health Research Ethics committee (S17/10/097). All procedures were in accordance with the ethical standards of the responsible committee on human experimentation (institutional and national) and with the Helsinki Declaration of 1975 , as revised in 2008 .

Informed written consent was waived by the ethics committee for all patients included in the study.

\section{Declaration}

The authors declare authorship of this article and that they have followed sound scientific research practice. This research is original and does not transgress plagiarism policies

\section{Author contributions:}

HSP: Study conceptualisation, data capture, data analysis, first draft preparation, manuscript revision and final draft preparation

NF: Data analysis, language and grammar correction and final draft review

MB: Data analysis, language and grammar correction and final draft review

\section{ORCID}

Pretorius HS (iD https://orcid.org/0000-0002-7419-0885

Ferreira N (D) https://orcid.org/0000-0002-0567-3373

Burger MC (iD https://orcid.org/0000-0003-2831-4960

\section{References}

1. Ilyas AM. Surgical approaches to the distal radius. Hand (N Y). 2011;6(1):8-17.

2. Itamura JM, Roidis NT, Chong AK, et al. Computed tomography study of radial head morphology. J Shoulder Elb Surg. 2008;17(2):347-54.

3. Malone PSC, Shaw OG, Lees VC. Anatomic relationships of the distal and proximal radioulnar joints articulating surface areas and of the radius and ulna bone volumes - implications for biomechanical studies of the distal and proximal radioulnar joints and forearm bones. Front Bioeng Biotechnol. 2016;4(July):1-7. https://doi.org/10.3389/fbioe.2016.00061.

4. Barrier ILO, L'Abbé EN. Sex determination from the radius and ulna in a modern South African sample. Forensic Sci Int. 2008;179(1):85.e1-7.

5. Köse A, Aydın A, Ezirmik N, et al. Alternative treatment of forearm double fractures: new design intramedullary nail. Arch Orthop Trauma Surg. 2014;134(1):1387-96. https://doi.org/10.1007/s00402-014-2058-9.
6. Alao U, Liew I, Yates J, Kerin C. Correlation between the length from the elbow to the distal interphalangeal joint of the little finger and the length of the intramedullary nail selected for femoral fracture fixation. Injury. 2018;49(11):2058-60. https://doi.org/10.1016/j.injury.2018.08.024.

7. Badkur $\mathrm{P}, \mathrm{Nath} \mathrm{S}$. Use of regression analysis in reconstruction of maximum bone length and living stature from fragmentary measures of the ulna. Forensic Sci Int. 1990;45(1-2):15-25.

8. Beşer CG, Demiryürek D, Özsoy H, et al. Redefining the proximal ulna anatomy. Surg Radiol Anat. 2014;36(10):1023-31.

9. Akpinar F, Aydinlioglu A, Tosun N, Tuncay İ. Morphologic evaluation of the ulna. Acta Orthop Scand. 2003;74(4):415-19.

10. Yong WJ, Tan J, Adikrishna A, et al. Morphometric analysis of the proximal ulna using three-dimensional computed tomography and computer-aided design: varus, dorsal, and torsion angulation. Surg Radiol Anat. 2014;36(8):763-68.

11. Pall Singh TS, Sadagatullah AN, Yusof AH. Morphology of distal radius curvatures: A CT-based study on the Malaysian Malay population. Singapore Med J. 2015;56(10):562-66.

12. Vroemen JC, Dobbe JGG, Jonges $R$, et al. Three-dimensional assessment of bilateral symmetry of the radius and ulna for planning corrective surgeries. $J$ Hand Surg Am. 2012;37(5):982-88. https://doi.org/10.1016/j.jhsa.2011.12.035.

13. Lamas $C$, Llusà $M$, Méndez $A$, et al. Intraosseous vascularity of the distal radius: Anatomy and clinical implications in distal radius fractures. Hand. 2009;4(4):418-23.

14. Rouleau DM, Canet F, Chapleau J, et al. The influence of proximal ulnar morphology on elbow range of motion. J Shoulder Elb Surg. 2012;21(3):38488. https://doi.org/10.1016/j.jse.2011.10.008.

15. Yörükoğlu A çağdaş, Demirkan AF, Akman A, et al. The effects of radial bowing and complications in intramedullary nail fixation of adult forearm fractures. Jt Dis Relat Surg. 2017;28(1):30-34.

16. Dave MB, Parmar KD, Sachde BA. The radial bow following square nailing in radius and ulna shaft fractures in adults and its relation to disability and function. Malaysian Orthop J. 2016;10(2):12-15.

17. Hanley EN. Instructional Course Lectures. J Bone Jt Surg. 2004;86(11):258 7-88. 